\title{
Optimized induction of beta common receptor enhances the neuroprotective function of erythropoietin in spinal cord ischemic injury
}

\author{
Katsuhiro Yamanaka, MD, PhD, Mohamed Eldeiry, MD, Muhammad Aftab, MD, Joshua Mares, BS, \\ Thomas J. Ryan, BS, Xianzhong Meng, MD, PhD, Michael J. Weyant, MD, Joseph C. Cleveland, Jr, MD, \\ David A. Fullerton, MD, and T. Brett Reece, MD
}

\section{ABSTRACT}

Background: Paraplegia remains the most feared complication of complex thoracoabdominal aortic intervention. Although erythropoietin (EPO) has demonstrated neuroprotective effects in spinal cord ischemia, it does not work until expression of the beta common receptor subunit of the EPO receptor $(\beta \mathrm{cR})$ is induced by ischemia. We hypothesized that the $\beta \mathrm{cR}$ can be induced by diazoxide (DZ), amplifying the neuroprotective effects of EPO in spinal cord ischemiareperfusion injury.

Methods: For the DZ time trial, adult male C57/BL6 mice received DZ $(20 \mathrm{mg} / \mathrm{kg}$ ) by oral gavage. Spinal cords were harvested after $0,12,24,36$, and 48 hours of administration. To evaluate optimal dosing, DZ was administered at $0,5,10,20$, and $40 \mathrm{mg} / \mathrm{kg}$. The expression of $\beta \mathrm{cR}$ was assessed by Western blot analysis. Five groups were studied: PBS (pretreatment)+PBS (immediately before), PBS +EPO, DZ+PBS, DZ +EPO, and sham (without cross-clamping). Spinal cord ischemia was induced by 4 minutes of thoracic aortic crossclamping. Functional scoring (Basso Mouse Score) was done at 12-hour intervals for 48 hours, and spinal cords were harvested for histological analysis.

Results: Western blot analysis demonstrated that optimal $\beta \mathrm{cR}$ up-regulation occurred at 36 hours after DZ administration, and the optimal DZ dosage for $\beta \mathrm{cR}$ induction was $20 \mathrm{mg} / \mathrm{kg}$. Motor function at 48 hours after treatment was significantly better preserved in the DZ+EPO group compared with all other groups, and was significantly better preserved in the DZ only and EPO only groups compared with control (PBS+PBS).

Conclusions: Pharmacologic up-regulation of $\beta \mathrm{cR}$ with DZ can increase the efficacy of EPO in preventing spinal cord ischemia and reperfusion injury. Improved understanding of this synergetic mechanism may serve to further prevent ischemic complications for high-risk aortic intervention. (J Thorac Cardiovasc Surg 2018;155:2505-16)

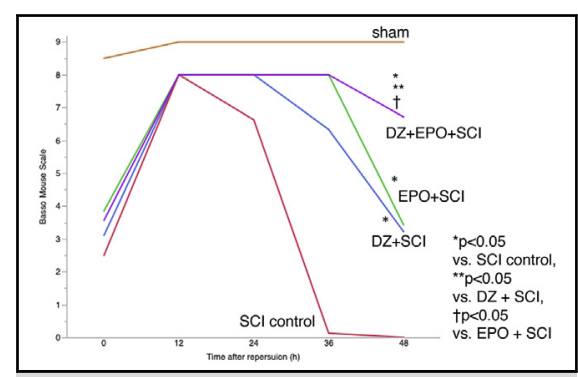

Postoperative motor function in each group.

Central Message

Treatment of mice subjected to spinal cord ischemia-reperfusion with diazoxide (DZ) plus erythropoietin (EPO) provides dramatically better preservation of motor function compared with either DZ or EPO alone.

Perspective

EPO and DZ are clinically available. Although EPO has shown a neuroprotective effect in the spinal cord, EPO does not work until the $\beta \mathrm{cR}$ subunit is induced by metabolic stress. Pretreatment of DZ up-regulated $\beta c \mathrm{R}$ expression, and treatment with the combination of $\mathrm{DZ}$ and EPO significantly preserved motor function in a murine model of SCI. This novel strategy may prevent paraplegia in aortic interventions.

See Editorial Commentary page 2517.
From the Division of Cardiothoracic Surgery, Department of Surgery, University of Colorado, Aurora, Colo.

Funded by the Department of Surgery, University of Colorado Denver.

Read at the 43rd Annual Meeting of The Western Thoracic Surgical Association, Colorado Springs, Colorado, June 21-24, 2017.

Received for publication July 12, 2017; revisions received Nov 15, 2017; accepted for publication Dec 11, 2017; available ahead of print March 6, 2018.

Address for reprints: Katsuhiro Yamanaka, MD, PhD, University of Colorado, Cardiothoracic Surgery, Mail Stop C310, 12631 E 17th Ave, Room 6601, Aurora, CO 80045 (E-mail: katsuhiro.yamanaka@ucdenver.edu).

$0022-5223 / \$ 36.00$

Copyright $(2018$ by The American Association for Thoracic Surgery

https://doi.org/10.1016/j.jtcvs.2017.12.132
Although the outcomes of thoracoabdominal aortic intervention have improved steadily in recent years, paraplegia after thoracoabdominal aortic repair remains a devastating postoperative complication. The number of patients put at risk by undergoing these operations is also increasing.

Scanning this QR code will take you to the article title page. 


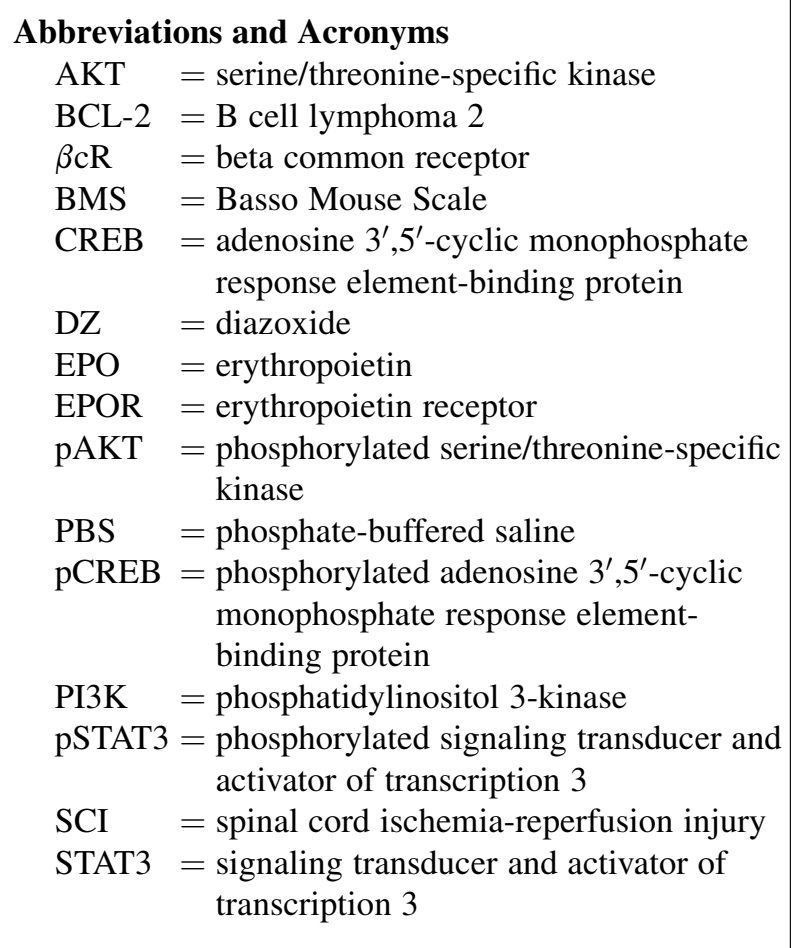

Although the extent of repair plays a major role, the incidence of postoperative spinal cord complications can be between $10 \%$ and $15 \%$ in the best centers. Despite ongoing efforts to provide protection from this injury, a universally accepted pharmacologic therapy remains to be established. ${ }^{2}$

Diazoxide (DZ; Proglycem) is an oral medication that can be used to manage symptomatic hypoglycemia. An ATP-dependent potassium channel opener, DZ has been shown to mediate the neuroprotective preconditioning effects against an ischemic insult. ${ }^{3}$ Erythropoietin (EPO) is widely recognized as an essential hormone for its role in hematopoiesis. Recent studies have shown that EPO has protective effects in a variety of tissues, including the kidneys, heart, brain, and spinal cord. ${ }^{4-6}$ Furthermore, we have reported on the protective mechanism of EPO in the mouse model of spinal cord ischemia-reperfusion injury (SCI). ${ }^{7}$

Recent investigations into the tissue protective effects of EPO have led to the identification of a unique receptor, distinct from the EPO receptor (EPOR), which mediates hematopoiesis. This unique tissue protective receptor is termed the beta common receptor $(\beta \mathrm{cR})$ subunit. $^{8}$ EPOR and $\beta \mathrm{cR}$ subunit expression is up-regulated in response to hypoxia and inflammatory cytokines, such as tumor necrosis factor- $\alpha$ and interleukin (IL)- $1 \beta .^{9,10}$ However, the molecular mechanisms of $\beta \mathrm{cR}$ subunit regulation are incompletely understood. ${ }^{9}$ Although neuroprotective effects of EPO have been implicated in the spinal cord, these effects require $\beta c R$ subunit up-regulation, which under
TABLE 1. The Basso Mouse Scale for locomotion

\begin{tabular}{|c|c|}
\hline Score & Characteristics \\
\hline 0 & No ankle movement \\
\hline 1 & Slight ankle movement \\
\hline 2 & Extensive ankle movement \\
\hline 3 & $\begin{array}{l}\text { Plantar placing of the paw with or without weight support, or } \\
\text { occasional, frequent } \\
\text {-OR - } \\
\text { consistent dorsal stepping but no plantar stepping }\end{array}$ \\
\hline 4 & Occasional plantar stepping \\
\hline 5 & $\begin{array}{l}\text { Frequent or consistent plantar stepping, no coordination } \\
\text {-OR- } \\
\text { frequent or consistent plantar stepping, some coordination, } \\
\text { paws rotated at initial contact and lift off }\end{array}$ \\
\hline 6 & $\begin{array}{l}\text { Frequent or consistent plantar stepping, some coordination, } \\
\text { paws parallel at initial contact } \\
\text {-OR- } \\
\text { frequent or consistent plantar stepping, mostly coordinated, } \\
\text { paws rotated at initial contact and lift off }\end{array}$ \\
\hline 7 & $\begin{array}{l}\text { Frequent or consistent plantar stepping, mostly coordinated, } \\
\text { paws parallel at initial contact and rotated at lift off }(\mathrm{P} / \mathrm{R}) \\
\text {-OR- } \\
\text { frequent or consistent plantar stepping, mostly coordinated, } \\
\text { paws parallel at initial contact and lift off }(\mathrm{P} / \mathrm{P}) \text {, and severe } \\
\text { trunk instability }\end{array}$ \\
\hline 8 & $\begin{array}{l}\text { Frequent or consistent plantar stepping, mostly coordinated, } \\
\text { paws parallel at initial contact and lift off }(\mathrm{P} / \mathrm{P}) \text {, and mild } \\
\text { trunk instability } \\
\text {-OR- } \\
\text { frequent or consistent plantar stepping, mostly coordinated, } \\
\text { paws parallel at initial contact and lift off (P/P), and } \\
\text { normal trunk stability and tail down or up and down }\end{array}$ \\
\hline 9 & $\begin{array}{l}\text { Frequent or consistent plantar stepping, mostly coordinated, } \\
\text { paws parallel at initial contact and lift off }(\mathrm{P} / \mathrm{P}) \text {, and } \\
\text { normal trunk stability and tail always up }\end{array}$ \\
\hline
\end{tabular}

physiological conditions requires an ischemic insult. ${ }^{8}$ Thus, in the present study, we aimed to pharmacologically induce $\beta \mathrm{cR}$ subunit up-regulation before ischemia to optimize the neuroprotective effect of EPO. We hypothesized that $\beta \mathrm{cR}$ subunit up-regulation by DZ before ischemia amplifies the neuroprotective effects of EPO in mice with SCI.

\section{MATERIALS AND METHODS Animals}

Adult male C57BL/6 mice (age 12-20 weeks; Charles River Laboratories, Wilmington, Mass) were used for all experiments. This study was approved by the Animal Care and Use Committee at the University of Colorado at Anschutz Medical Campus, and all procedures conformed to the US National Institutes of Health's Guide for the Care and Use of Laboratory Animals.

\section{Materials}

DZ was purchased from Teva Pharmaceutical (North Wales, Pa). Recombinant erythropoietin from mouse was purchased from Sigma-Aldrich (St. Louis, Mo). Anti- $\beta$ cR and anti-EPOR were purchased from Santa 

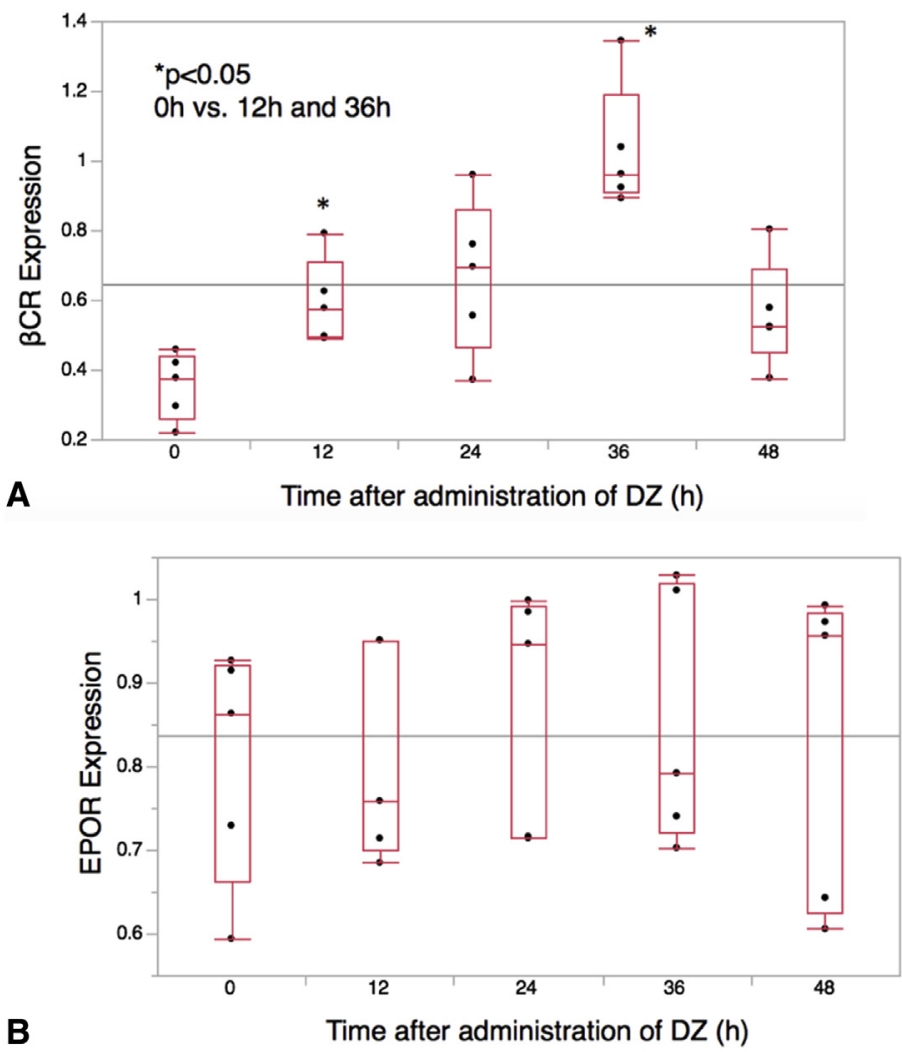

B

Time after administration of $D Z(h)$

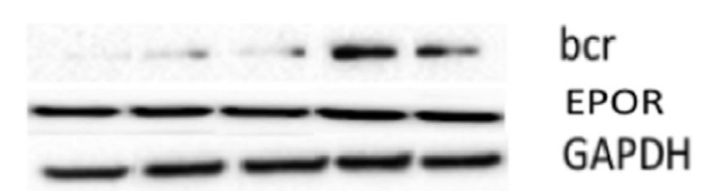

C $\quad 0 \mathrm{~h} 12 \mathrm{~h} \quad 24 \mathrm{~h} \quad 36 \mathrm{~h} \quad 48 \mathrm{~h}$

FIGURE 1. Time trials of diazoxide (DZ). A, Beta common receptor $(\beta c R)$ expression. The expression of $\beta \mathrm{cR}$ peaked at 36 hours after injection of DZ. B, Erythropoietin receptor (EPOR) expression. The expression of EPOR remained flat. C, $\beta \mathrm{cR}$, EPOR, and glyceraldehyde 3-phosphate dehydrogenase $(G A P D H)$ expression were analyzed by immunoblotting. Results are expressed as mean \pm standard error of the mean $(\mathrm{SEM}) ; \mathrm{n}=5$.

Cruz Biotechnology (Dallas, Tex). Anti- signaling transducer and activator of transcription 3 (STAT3), anti-phosphorylated STAT3 (pSTAT3), anti-serine/ threonine-specific kinase (AKT), anti-phosphorylated AKT (pAKT), antiCREB, and anti-phosphorylated CREB (pCREB) were purchased from Cell Signaling Technology (Danvers, Mass).

\section{Experimental Design}

A time trial was carried out using DZ ( $20 \mathrm{mg} / \mathrm{kg}$ ) given to the mice by oral gavage to determine the optimal timing of administration. Spinal cords were harvested at $0(n=5), 12(n=5), 24(n=5), 36(n=5)$, or $48(n=5)$ hours after $\mathrm{DZ}$ administration, and $\beta \mathrm{cR}$ expression was evaluated by Western blot analysis. After the time trial test, a dosage trial was similarly carried out using $\mathrm{DZ}(0,5,10,20$, and $40 \mathrm{mg} / \mathrm{kg} ; \mathrm{n}=5$ at each dosage $)$ administered by oral gavage, and $\beta \mathrm{cR}$ expression was analyzed by Western blot analysis.

To determine the optimal dose of EPO, once- or twice-daily intraperitoneal injection of EPO ( 10 or $40 \mu \mathrm{g} / \mathrm{kg}$ ) was administered 4 hours before surgery ( $\mathrm{n}=4$ at each dosage). After surgery, the postoperative hind limb motor function was observed for 48 hours.

For the present study, mice were divided into 5 groups: sham $(n=4)$, SCI control (PBS pretreatment plus PBS 4 hours before surgery; $\mathrm{n}=10$ ), EPO+SCI (PBS pretreatment plus EPO 4 hours before surgery; $\mathrm{n}=7$ ), DZ+SCI (DZ pretreatment plus PBS 4 hours before surgery; $\mathrm{n}=7$ ), and $\mathrm{DZ}+\mathrm{EPO}+\mathrm{SCI}$ (DZ pretreatment plus EPO 4 hours before surgery; $\mathrm{n}=7$ ). In these groups, a mouse model of SCI was produced. Motor function was observed at 12-hour intervals up to 48 hours, and spinal cords were harvested to analyze the histological changes. The mice who died after surgery was excluded from the study.

To investigate the survival pathway of these drugs, spinal cords in each group were removed at $0,1,2,4$, and 6 hours after injection of PBS or EPO without surgery, and the activation of AKT, STAT3, and CREB was evaluated by Western blot analysis.

\section{Surgical Procedures}

Anesthesia was induced by inhalation of 5\% isoflurane and maintained with inhalation of $1.5 \%$ isoflurane $/ 100 \%$ oxygen mixture. The operation was performed with the mouse in the supine position. A midline cervicosternal incision was used to expose the aortic arch. Rectal temperature was monitored and maintained at $36.5 \pm 0.5{ }^{\circ} \mathrm{C}$ with a heating pad (Vestavia Scientific, Birmingham, Ala). A laser Doppler blood flow monitor (Moor Instruments, Axminster, United Kingdom) was placed over the left femoral artery to confirm a minimum $90 \%$ reduction in aortic distal flow during aortic occlusion. ${ }^{4}$ Heparin (400 IU/kg) was injected intraperitoneally. Under direct visualization, the aortic arch between the left common carotid artery and the left subclavian artery was clamped for 4 minutes. Once the clamps were removed, the chest was closed. Sham-treated mice underwent the same procedure but without aortic clamping.

\section{Assessment of Motor Function}

The Basso Mouse Scale (BMS) was used to evaluate the motor function of the mice following SCI. ${ }^{11}$ Scores for the BMS range from 0 for complete paraplegia to 9 for normal function (Table 1). The mice were scored at 0 , 12, 24, 36 and 48 hours after reperfusion. Postoperative motor function was evaluated by blinded observers.

\section{Western Blot Analysis}

Spinal cords were removed and homogenized in EDTA-free complete lysis-M buffer (Roche Diagnostics, Indianapolis, Ind). Supernatant was 


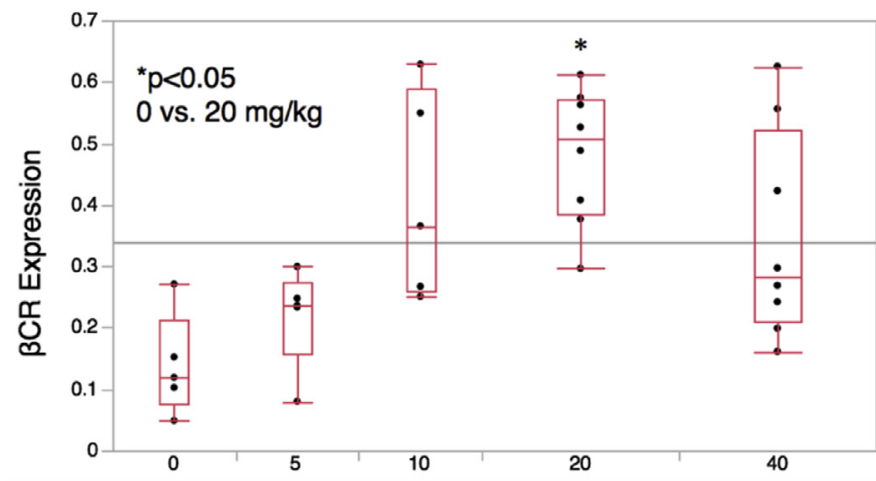

A

Dosage of DZ $(\mathrm{mg} / \mathrm{kg})$

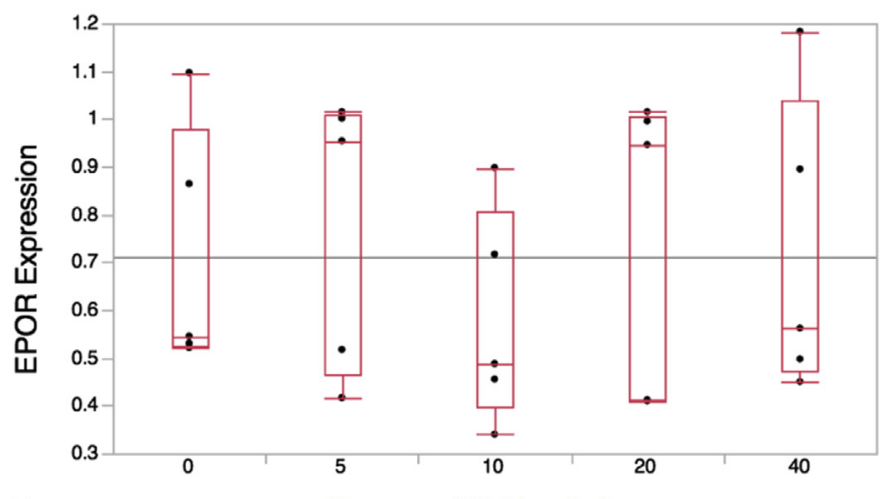

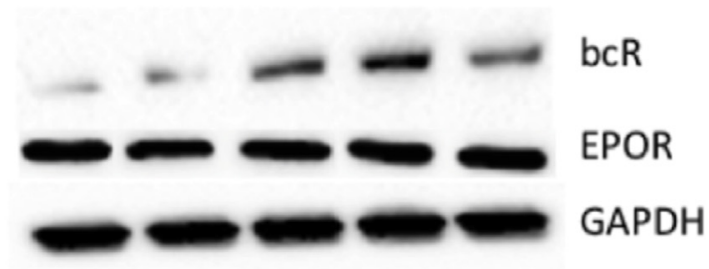

C $\quad \begin{array}{lllll}0 & 5 & 10 & 20 & 40 \mathrm{mg} / \mathrm{kg}\end{array}$

B

Dosage of DZ $(\mathrm{mg} / \mathrm{kg})$

FIGURE 2. Dose trials of diazoxide (DZ). A, Beta common receptor $(\beta c R)$ expression. The expression of $\beta c R$ peaked at $20 \mathrm{mg} / \mathrm{kg}$. B, Erythropoietin receptor $(E P O R)$ expression. The expression of EPOR remained unchanged. C, $\beta \mathrm{cR}$, EPOR, and glyceraldehyde 3-phosphate dehydrogenase $(G A P D H)$ were analyzed by immunoblotting. Results are expressed as mean \pm standard error of the mean (SEM); $\mathrm{n}=5$.

placed in $2 \times$ Laemmli sample buffer with $\beta$-mercaptoethanol and boiled for 10 minutes at $100^{\circ} \mathrm{C}$. Samples were loaded into $4 \%$ to $20 \%$ gradient gels (Bio-Rad, Hercules, Calif), run at $160 \mathrm{~V}$ for 50 minutes, and then transferred to a nitrocellulose membrane. After blocking in 5\% milk with bovine serum albumin, the membranes were incubated overnight at $4{ }^{\circ} \mathrm{C}$ in $1: 1000$ primary antibody (anti- $\beta \mathrm{cR}$, -EPO, -STAT3, -pSTAT3, -AKT, -pAKT, -CREB, and -pCREB). After the membranes were washed in phosphate-buffered saline with $0.05 \%$ Tween 20 (Sigma-Aldrich, St. Louis, Mo), they were incubated at room temperature in secondary antibody for 1 hour. The membranes were washed again, and SuperSignal West Dura Extended-Duration Substrate (Thermo Fisher Scientific) was used to detect the target band. The density of target bands was analyzed with ImageJ.

\section{Tissue Sampling and Histological Analysis}

Mice were euthanized at 48 hours after reperfusion. Lumbar enlargement of the spinal cord at the T8 to L3 vertebral level was harvested en bloc. Spinal cords were preserved in $10 \%$ formalin for at least 24 hours, embedded in paraffin, and sectioned. Hematoxylin and eosin staining and quantitative analysis of viable neurons within the anterior horn of the spinal cord were performed in a blinded fashion. The removed spinal cord was divided into 3 parts. One section of each part was collected blindly on a glass slide, and viable neurons were counted by a blinded observer. Neurons containing prominent nucleoli and loose chromatin were defined as normal.

\section{Statistical Analysis}

Data are presented as mean \pm standard error. Statistical analysis was performed using repeated-measures and Kruskal-Wallis nonparametric analysis of variance with Steel-Dwass and Steel post hoc tests using JMP for Mac, version 9.0.2 (SAS Institute, Cary, NC). A $P$ value $<.05$ was considered significant for all statistical comparisons.

\section{RESULTS}

\section{Time and Dose Trials of $\mathrm{DZ}$}

Data from the time trial demonstrated that a DZ dose of $20 \mathrm{mg} / \mathrm{kg}$ significantly increased $\beta \mathrm{cR}$ expression at 12 and 36 hours after DZ administration $(P<.05)$, with a peak at 36 hours. On the other hand, EPOR expression remained unchanged (Figure 1). A DZ dose of $20 \mathrm{mg} / \mathrm{kg}$ significantly up-regulated the $\beta \mathrm{cR}$ expression $(P<.05)$. Again, EPOR expression remained unchanged (Figure 2).

\section{EPO Dosage Trial}

The hind limb motor function did not change significantly after surgery across the 4 groups ( 10 or $40 \mu \mathrm{g} / \mathrm{kg}$ once or twice daily), but the BMS scores were highest in mice who received a single daily EPO injection of $40 \mu \mathrm{g} / \mathrm{kg}$ (Figure 3).

\section{Postoperative Motor Function}

Sham-treated mice showed no functional deficits after recovery from surgery. All mice in the SCI control group developed permanent paraplegia by 36 hours after 


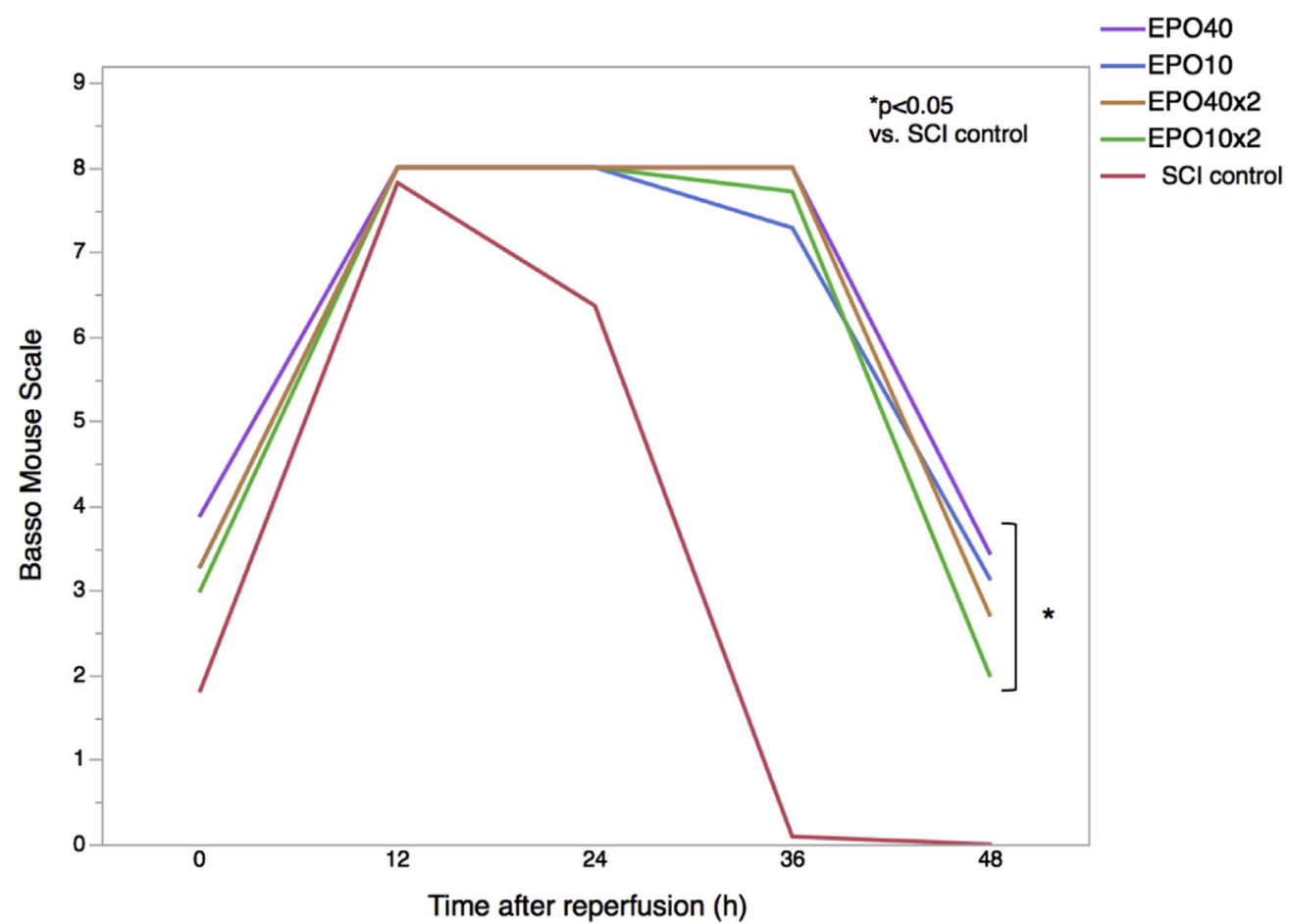

FIGURE 3. Dose trial of erythropoietin $(E P O)$ for postoperative motor function. Mice treated with EPO only exhibited more significant attenuation of motor function compared with spinal cord ischemia-reperfusion injury $(S C I)$ control mice. There were no significant differences between EPO treatment groups; $\mathrm{n}=7$.

reperfusion. The motor function in mice treated with DZ only or EPO only improved relative to the SCI control group $(P<.05)$. The group treated with $\mathrm{DZ}+\mathrm{EPO}+\mathrm{SCI}$ showed the most substantial preservation of hind limb motor function among all the treatment groups $(P<.05)$ (Figure 4$)$.

\section{Histological Changes}

Hematoxylin and eosin staining showed a significant reduction in the number of viable neurons and the severe vacuolization in the treatment group with SCI control compared with sham-treated mice (Figure 5). Blinded quantification of these viable neurons showed that mice treated with DZ only and EPO only had more viable neurons than the mice in the SCI control group $(P<.05)$. However, the combination treatment in the DZ+EPO group showed the most substantial preservation of motor neurons, with a significant difference compared with the sham group (Figure 6).

\section{Survival Pathway Activation}

Activation of AKT, STAT3, and CREB in mice treated with DZ+EPO peaked at 4 hours after EPO injection (Figure 7). As for the activation of AKT, AKT activation was increased by treatment; however, the increase was not statistically significant. In terms of CREB activation, only $\mathrm{DZ}+\mathrm{EPO}$ significantly increased CREB activation compared with SCI control. The activation of STAT3 in both the $\mathrm{DZ}+\mathrm{SCI}$ and $\mathrm{EPO}+\mathrm{SCI}$ groups was greater than that in the SCI control group $(P<.05)$. This activation was more prominent in the $\mathrm{DZ}+\mathrm{EPO}+\mathrm{SCI}$ group compared with the other groups $(P<.05)$ (Figure 8, $A-C)$.

\section{DISCUSSION}

In the present study, we found that pretreatment with DZ significantly up-regulated $\beta \mathrm{cR}$ expression. Mice treated with DZ only or EPO only showed significant improvement compared with SCI control mice. Furthermore, the motor function of mice treated with $\mathrm{DZ}+\mathrm{EPO}+\mathrm{SCI}$ was significantly better than that of mice treated with $\mathrm{DZ}+\mathrm{SCI}$ or with EPO+SCI through activation of STAT3 (Figure 9).

Paraplegia is a devastating complication that can occur after successful aortic intervention despite evolving methods to protect the spinal cord. Postoperative paraplegia is classified as immediate or delayed according to the time of onset. ${ }^{12}$ Although immediate paraplegia is an irreversible neuronal injury caused by severe ischemia during surgery, delayed paraplegia is commonly reversible. Delayed paraplegia has been speculated to be the result of various events, such as ischemic reperfusion injury, immunologic response, and postoperative reduced perfusion due to hypotension and occlusion of the reconstructed intercostal artery. ${ }^{13-15}$ To further elucidate the mechanism of SCI, we have developed a murine model of SCI. ${ }^{4,16-18}$ 


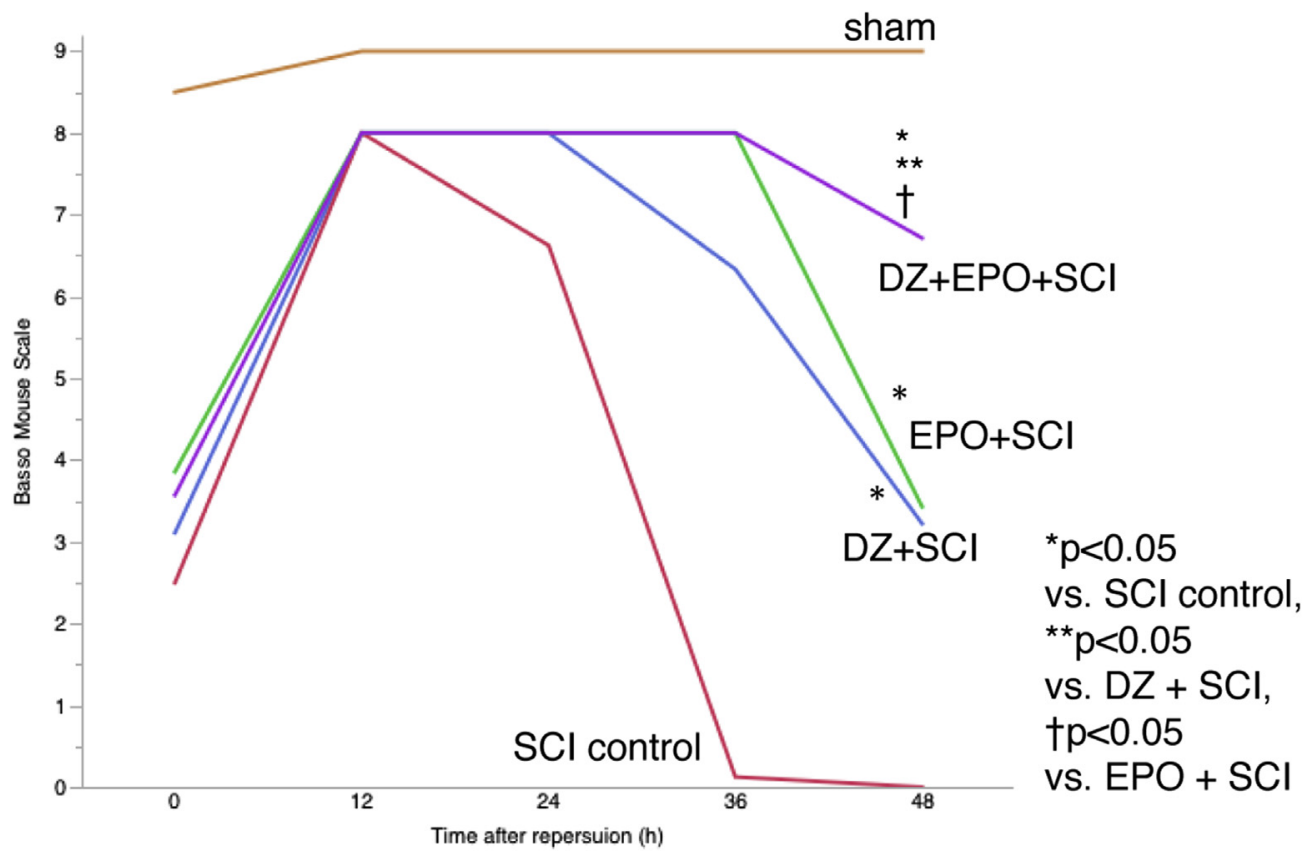

FIGURE 4. Postoperative motor function. Motor function was significantly better preserved in the diazoxide (DZ) only (mean Basso Mouse Scale [BMS] score, $3.2 \pm 0.6)$ and erythropoietin $(E P O)$ only (mean BMS score, $3.4 \pm 0.5)$ groups compared with the spinal cord ischemia-reperfusion injury ( $S C I$ ) control group (mean BMS score, $0.0 \pm 0.4$ ). DZ+EPO (mean BMS score, $6.7 \pm 0.4$ ) was associated with dramatically improved motor function compared with DZ only and EPO only. The mean BMS score of the sham group was $9.0 \pm 0.1$.

EPO has tissue protective and hematopoietic activities. Leist and colleagues have reported that the EPOmediated tissue protective receptor is distinct from the hematopoietic receptor (EPOR). ${ }^{19}$ The hematopoietic receptor is an EPOR/EPOR homodimer, whereas the tissue protective receptor is reported to be an $\mathrm{EPOR} / \beta \mathrm{cR}$

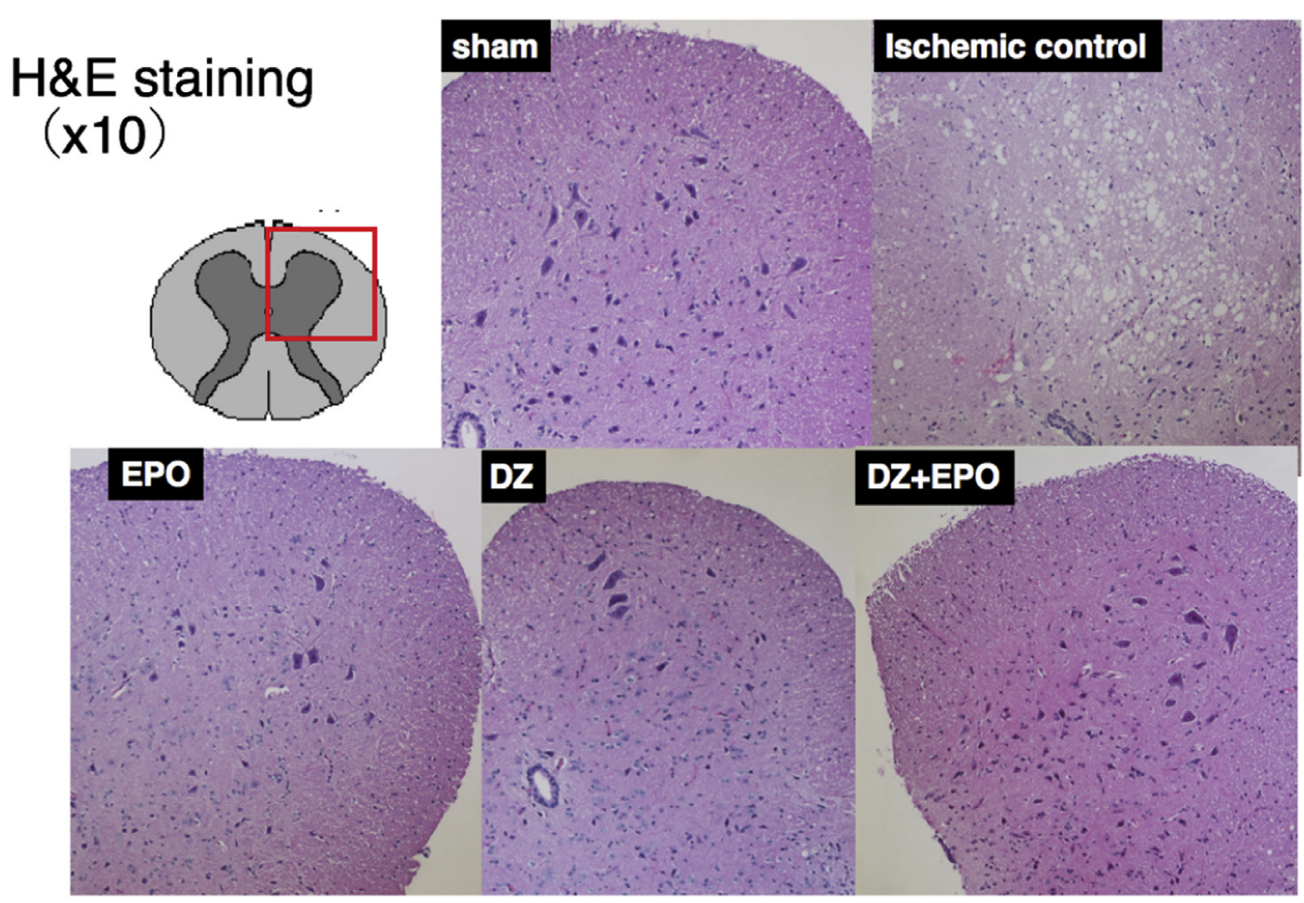

FIGURE 5. Hematoxylin and eosin staining. There were fewer viable neurons and severe vacuolization in the spinal cord ischemia-reperfusion injury (SCI) control group. Mice treated with diazoxide and erythropoietin $(D Z+E P O)$ showed a more normal appearance. 


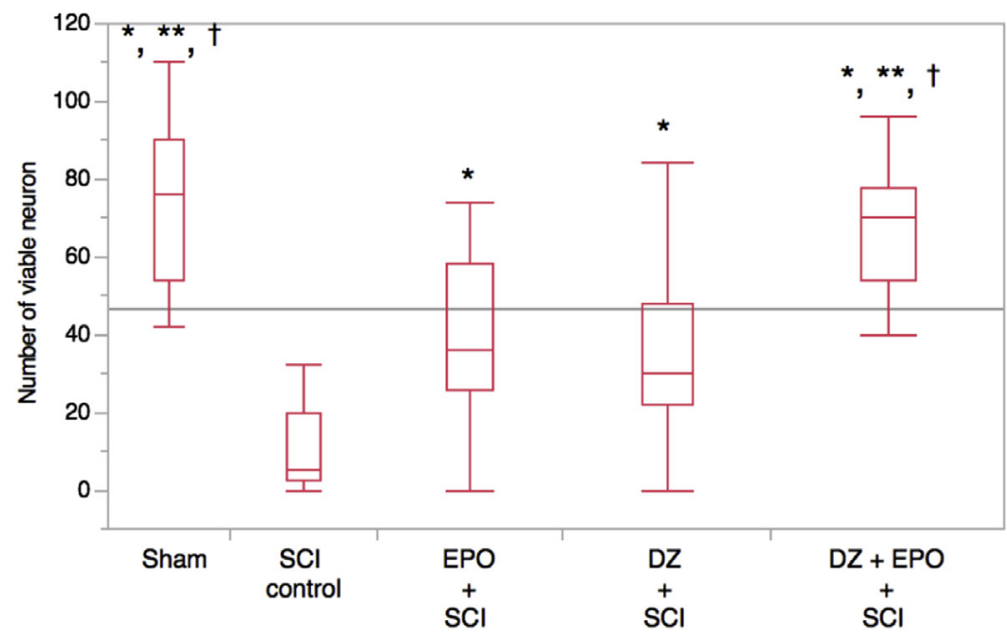

${ }^{\star} \mathrm{p}<0.05$ vs. SCI control

** $\mathrm{p}<0.05$ vs. $\mathrm{EPO}+\mathrm{SCl}$

tp<0.05 vs. $\mathrm{DZ}+\mathrm{SCl}$

FIGURE 6. The number of viable anterior horn neurons. Mice treated with diazoxide ( $D Z$ ) only or erythropoietin $(E P O)$ only had more viable neurons than spinal cord ischemia-reperfusion injury $(S C I)$ control mice. Mice treated with DZ+EPO had significantly more viable neurons than those treated with DZ only or with EPO only.

heterodimer ( $\beta \mathrm{cR}$ subunit). $\beta \mathrm{cR}$ is a type 1 cytokine receptor that responds to IL-3, IL-5, and granulocytemacrophage colony-stimulating factor (GM-CSF) (also known as CD131). ${ }^{20}$ We have previously shown functional improvement in mice with SCI due to the administration of $\mathrm{EPO}^{7,21}$; however, the protective effect of EPO was not
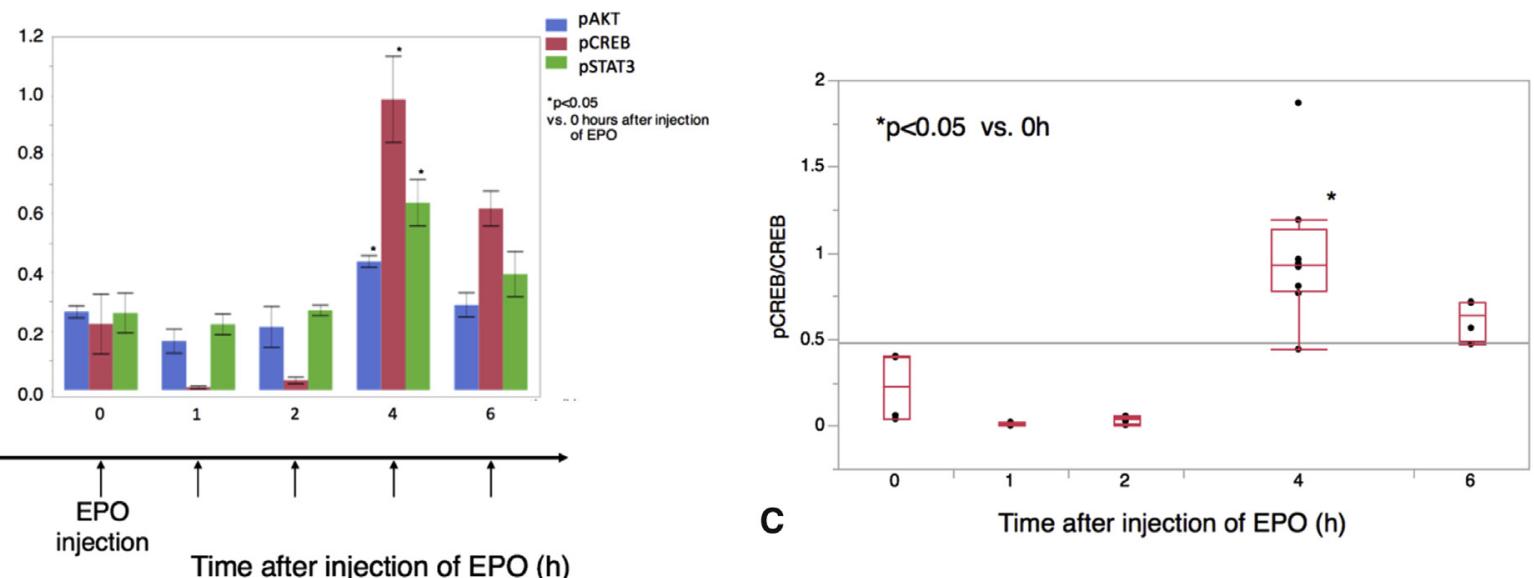

A Time after injection of EPO $(\mathrm{h})$
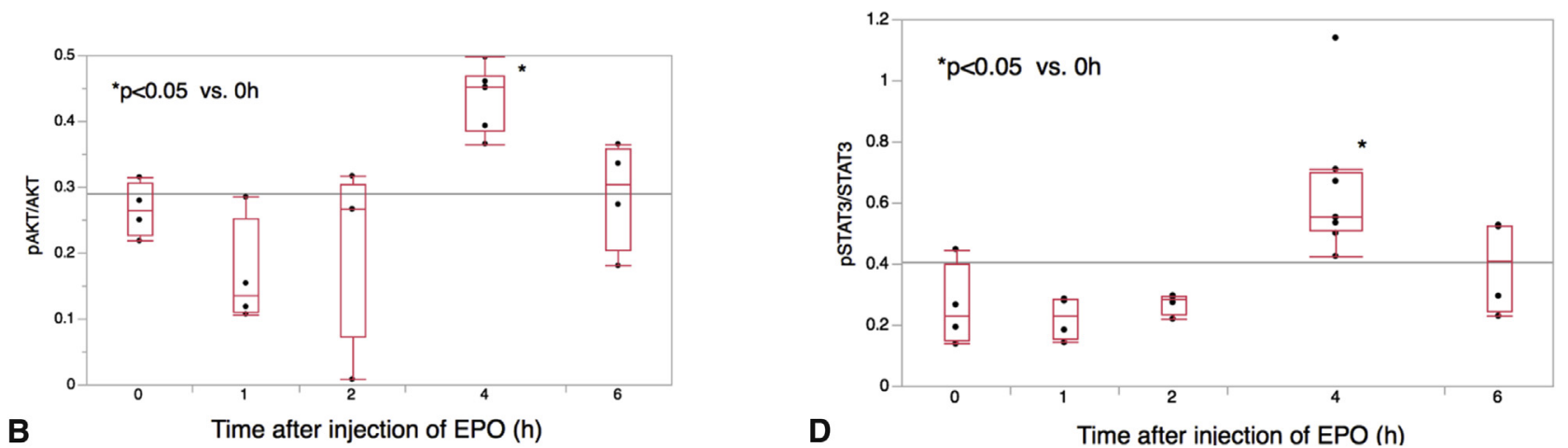

FIGURE 7. A, Activation of serine/threonine-specific kinase (AKT), adenosine $3^{\prime}, 5^{\prime}$-cyclic monophosphate response element-binding protein $(C R E B)$, and signaling transducer and activator of transcription 3 (STAT3) in the diazoxide $(D Z)+$ erythropoietin $(E P O)+$ spinal cord ischemia-reperfusion injury (SCI) group after injection of EPO without surgery. B, AKT. C, CREB. D, STAT3. The expression levels of phosphorylated AKT (pAKT), phosphorylated CREB $(p C R E B)$, and phosphorylated STAT3 ( $p S T A T 3)$ reached peak levels at 4 hours after EPO injection. $\mathrm{n}=5$. 

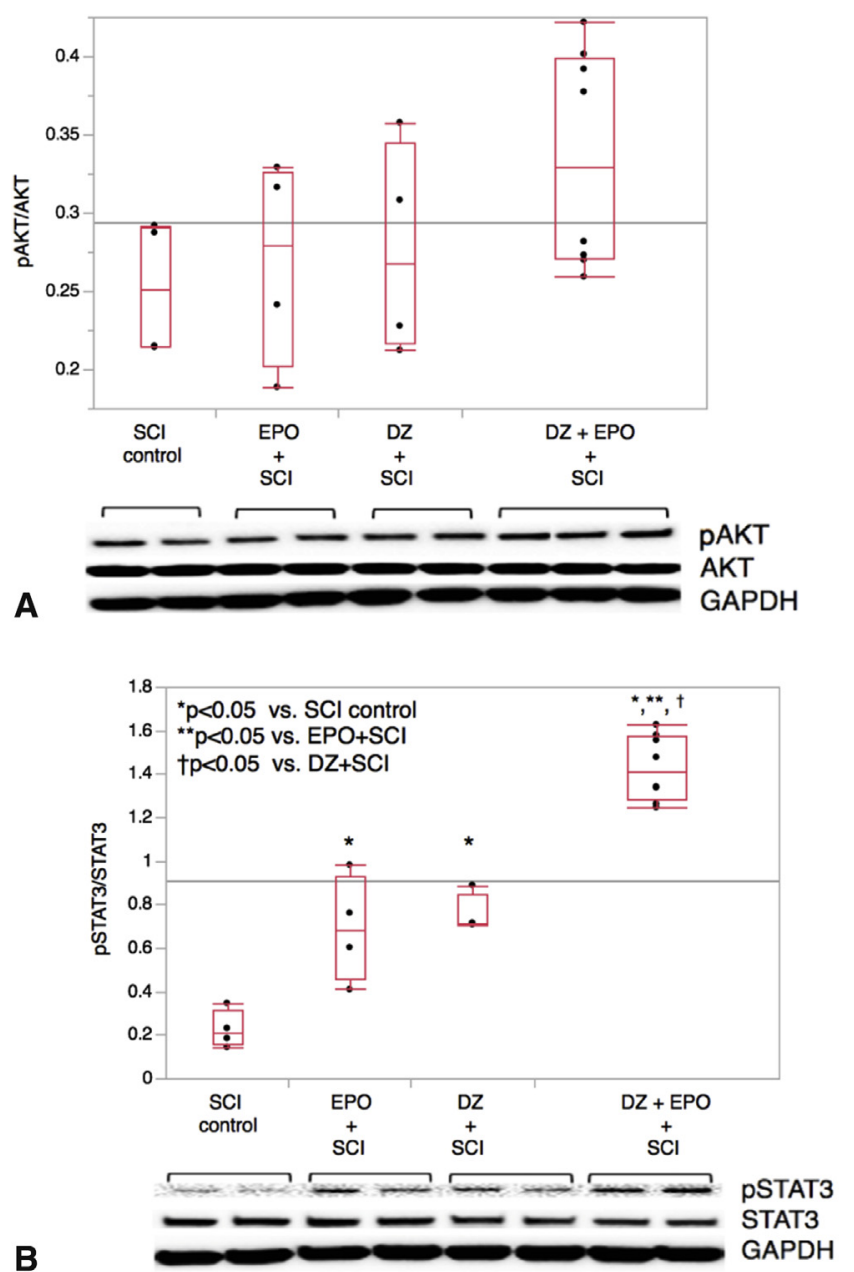

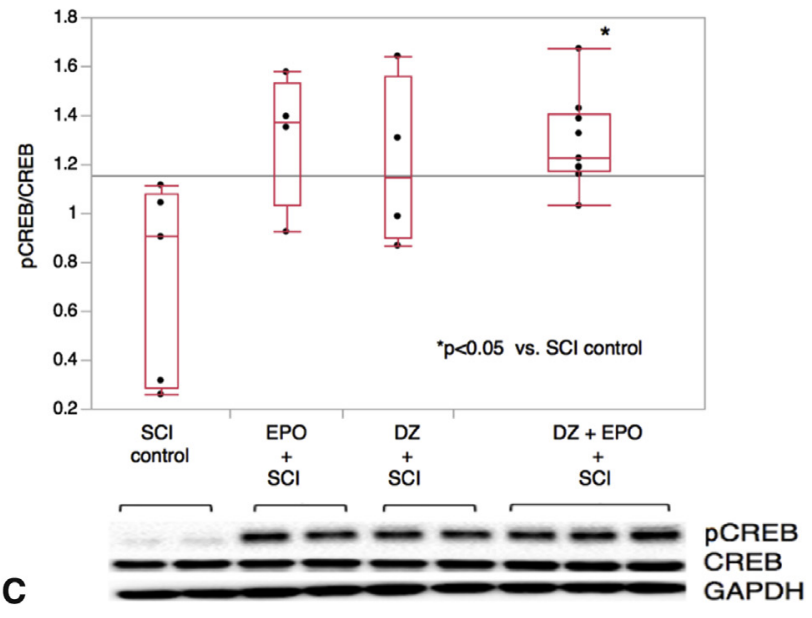

FIGURE 8. A, Activation of serine/threonine-specific kinase ( $A K T)$. AKT activation was increased by diazoxide $(D Z)$ only, erythropoietin $(E P O)$ only, and $\mathrm{DZ}+\mathrm{EPO}$ treatments; however, this increase was not statistically significant. B, Activation of signaling transducer and activator of transcription 3 (STAT3). EPO only and DZ only treatments significantly increased phosphorylated STAT3 (pSTAT3) compared with the SCI control group. DZ+EPO treatment drastically increased pSTAT3 compared with EPO only and DZ only treatment. C, Activation of adenosine $3^{\prime}, 5^{\prime}$-cyclic monophosphate response elementbinding protein $(C R E B)$ was significantly increased by DZ+EPO treatment; however, there were significant differences among the $\mathrm{EPO}+\mathrm{SCI}, \mathrm{DZ}+\mathrm{SCI}$, and DZ+EPO+SCI groups. $p A K T$, Phosphorylated AKT; $S C I$, spinal cord ischemia-reperfusion injury; GAPDH, glyceraldehyde 3-phosphate dehydrogenase; $p C R E B$, phosphorylated CREB.

seen until $\beta \mathrm{cR}$ subunit expression was induced by ischemic stress. To further pursue the neuroprotective mechanisms of EPO, we have focused on the $\beta \mathrm{cR}$ subunit. $^{10}$

In normal tissue, expression of the $\beta \mathrm{cR}$ subunit is generally low, but is significantly up-regulated by metabolic stress. Afterward, EPO is produced at the periphery of the damaged area, but its effects are transient and relatively weak. Moreover, EPO production is suppressed by the high level of inflammatory cytokines. ${ }^{8,19}$ Therefore, to obtain the maximum protection from the injury, EPO is administered, and the $\beta \mathrm{cR}$ subunit needs to be available for activation. We were able to achieve a significant upregulation of $\beta \mathrm{cR}$ before ischemia using DZ.
Experimental studies have shown that the $\beta \mathrm{cR}$ subunit activates multiple signaling pathways. In the present study, we focused on preparing the tissue for protection before the ischemia. Mice treated with $\mathrm{DZ}+\mathrm{EPO}$, which produced the most significant preservation of motor function after surgery, had significantly increased activation of STAT3 at 4 hours after EPO injection. STAT3 is involved in the blockage of inflammation-induced apoptosis. ${ }^{10}$ Furthermore, in addition to its antiapoptotic effects, STAT3 exerts protective effects through a wide range of signaling pathways. Lung and colleagues ${ }^{22}$ reported that superoxide dismutase 2 expression through STAT3 activation is neuroprotective in mouse cerebral ischemia. Oshima and colleagues $^{23}$ showed that metallothionein, an endogenous 


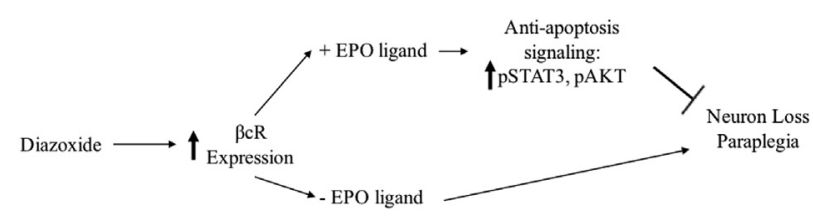

FIGURE 9. Signaling pathway through beta common receptor $(\beta c R)$ subunit induction with diazoxide (DZ). Occupancy of the $\beta \mathrm{cR}$ subunit by exogenous erythropoietin (EPO), which is induced by DZ, leads to phosphorylation of signaling transducer and activator of transcription 3 (STAT3) and serine/threonine-specific kinase (AKT), followed by prevention of neuronal loss. pSTAT3, Phosphorylated STAT3; $p A K T$, phosphorylated AKT.

protective agent that acts as a free radical scavenger and a stabilizer of biomembranes, is induced by STAT $3{ }^{23}$ Bolli and colleagues ${ }^{24}$ demonstrated that activation of STAT3 is associated with increased expression of heme oxygenase 1 , which protects cells from injury evoked by various oxidative stresses. In addition, $\mathrm{Fu}$ and colleagues ${ }^{25}$ indicated STAT3 activation is implicated in the activation of neural stem cell differentiation. As described above, STAT3dependent pathways play a significant role in cell survival. A previous study showed that EPO is present in cerebral spinal fluid at 1 hour after intraperitoneal injection, and its concentration peaks at approximately 4 hours after injection. ${ }^{26}$ Activation of STAT3, AKT, and CREB also peaked at 4 hours after injection of EPO in that study. Optimized induction of $\beta \mathrm{cR}$ expression and optimal administration of EPO brought about synergetic neuroprotective effects through the activation of STAT3.

The number of patients with extensive aortic disease has been increasing in recent years. ${ }^{27}$ However, no highly effective pharmacotherapy has been established as protective against SCI. We found that $\beta \mathrm{cR}$ expression was significantly up-regulated at 12 hours after DZ administration and reached a peak at 36 hours. Therefore, it is likely that our combination treatment would be most effective in elective cases in clinical practice. However, many patients with aortic disease often require emergency intervention. To expand the clinical applications, we need further studies evaluating the delivery and pharmacokinetics of DZ and EPO in the spinal cord. Furthermore, K-ATP channel activation requires further investigation to allow for more targeted therapy. Postoperative administration of $\mathrm{DZ}+\mathrm{EPO}$ combination treatment and other ATP-dependent potassium channel openers should be investigated for the potential to move into human trials.

This study has some limitations. First, blood pressure was not measured in the intraoperative or postoperative setting owing to the need for invasive monitoring, which would contribute to the morbidity. Second, isoflurane was used for anesthesia. Although isoflurane has been reported to have neuroprotective effects, its use has several advantages. It allows for rapid induction and recovery, as well as precise control of the depth and duration of anesthesia. Furthermore, it allows for a stable cardiac rhythm and preservation of cardiac output. Finally, we demonstrated that DZ enhances the neuroprotective effects of EPO through a synergetic mechanism. However, it is possible that the drug combination of DZ and EPO is involved in multiple protective pathways. We showed that treatment with DZ only or EPO only exhibited neuroprotective effects. Therefore, it is possible that our results were due to the additive effect of each individual drug. However, $\beta \mathrm{cR}$ expression was induced by $\mathrm{DZ}$, and $\beta \mathrm{cR}$ is a specific receptor of EPO. Considering the association between $\beta \mathrm{cR}$ and EPO, the optimized induction of $\beta \mathrm{cR}$ expression before ischemia is extremely important for maximizing EPO's neuroprotective function. Further research into this synergetic mechanism may allow for the development of specific target therapies that can ameliorate ischemic complications following aortic interventions.

\section{CONCLUSIONS}

DZ and EPO individually exhibit neuroprotective effects in mice undergoing SCI. These effects are modest and do not appear to completely prevent paraplegia. Pretreatment of mice with $\mathrm{DZ}$ up-regulates $\beta \mathrm{cR}$ subunit expression before ischemia. In combination, when given before SCI, DZ and EPO exhibit amplified neuroprotective effects in mice undergoing SCI through the up-regulation of $\beta \mathrm{cR}$ subunit. Further elucidation of this synergetic mechanism may contribute to the prevention of delayed paraplegia following aortic intervention.

\section{Conflict of Interest Statement}

Authors have nothing to disclose with regard to commercial support.

\section{References}

1. Masuda M, Okumura M, Doki Y, Endo S, Hirata Y, Kobayashi J, et al. Thoracic and cardiovascular surgery in Japan during 2014: annual report by the Japanese Association for Thoracic Surgery. Gen Thorac Cardiovasc Surg. 2016;64: 665-97.

2. Okita Y. Fighting spinal cord complication during surgery for thoracoabdominal aortic disease. Gen Thorac Cardiovasc Surg. 2011;59:79-90.

3. Nakagawa I, Wajima D, Tamura K, Nishimura F, Park YS, Nakase H. The neuroprotective effect of diazoxide is mediated by mitochondrial ATP-dependent potassium channels in a rat model of acute subdural hematoma. J Clin Neurosci. 2013:20:144-7.

4. Smith PD, Puskas F, Meng X, Cho D, Cleveland JC Jr, Weyant MJ, et al. Ischemic dose-response in the spinal cord: both immediate and delayed paraplegia. J Surg Res. 2012;174:238-44.

5. Chateauvieux S, Grigorakaki C, Morceau F, Dicato M, Diederich M. Erythropoietin, erythropoiesis and beyond. Biochem Pharmacol. 2011;82:1291-303.

6. Brines M, Cerami A. Erythropoietin-mediated tissue protection: reducing collateral damage from the primary injury response. J Intern Med. 2008;264:405-32.

7. Mares JM, Foley LS, Bell MT, Bennett DT, Freeman KA, Meng X, et al. Erythropoietin activates the phosporylated cAMP [adenosine 3',5'-cyclic monophosphate] response element-binding protein pathway and attenuates delayed 
paraplegia after ischemia-reperfusion injury. J Thorac Cardiovasc Surg. 2015; 149:920-4.

8. Brines M, Cerami A. The receptor that tames the innate immune response. $\mathrm{Mol}$ Med. 2012;18:486-96.

9. Wallach I, Zhang J, Hartmann A, van Landeghem FK, Ivanova A, Klar M, et al Erythropoietin-receptor gene regulation in neuronal cells. Pediatr Res. 2009;65: 619-24.

10. Foley LS, Fullerton DA, Bennett DT, Freeman KA, Mares J, Bell MT, et al. Spinal cord ischemia-reperfusion injury induces erythropoietin receptor expression. Ann Thorac Surg. 2015;100:41-6; discussion 46.

11. Basso DM, Fisher LC, Anderson AJ, Jakeman LB, McTigue DM, Popovich PG. Basso Mouse Scale for locomotion detects differences in recovery after spinal cord injury in five common mouse strains. J Neurotrauma. 2006;23:635-59.

12. Crawford ES, Mizrahi EM, Hess KR, Coselli JS, Safi HJ, Patel VM. The impact of distal aortic perfusion and somatosensory evoked potential monitoring on prevention of paraplegia after aortic aneurysm operation. J Thorac Cardiovasc Surg. 1988;95:357-67.

13. Yamanaka K, Sasaki N, Fujita Y, Kawamoto A, Hirata K, Okita Y. Impact of acquired and innate immunity on spinal cord ischemia and reperfusion injury. Gen Thorac Cardiovasc Surg. 2016;64:251-9.

14. Maniar HS, Sundt TM III, Prasad SM, Chu CM, Camillo CJ, Moon MR, et al. Delayed paraplegia after thoracic and thoracoabdominal aneurysm repair: a continuing risk. Ann Thorac Surg. 2003;75:113-9; discussion 11920.

15. Etz CD, Luehr M, Kari FA, Bodian CA, Smego D, Plestis KA, et al. Paraplegia after extensive thoracic and thoracoabdominal aortic aneurysm repair: does critical spinal cord ischemia occur postoperatively? J Thorac Cardiovasc Surg. 2008; 135:324-30.

16. Bell MT, Reece TB, Smith PD, Mares J, Weyant MJ, Cleveland JC Jr, et al Reproducible paraplegia by thoracic aortic occlusion in a murine model of spinal cord ischemia-reperfusion. J Vis Exp. 2014;85:50910.

17. Smith PD, Puskas F, Meng X, Lee JH, Cleveland JC Jr, Weyant MJ, et al. The evolution of chemokine release supports a bimodal mechanism of spinal cord ischemia and reperfusion injury. Circulation. 2012;126(11 Suppl 1): S110-7.

18. Bell MT, Puskas F, Agoston VA, Cleveland JC Jr, Freeman KA, Gamboni F, et al. Toll-like receptor 4-dependent microglial activation mediates spinal cord ischemia-reperfusion injury. Circulation. 2013;128(11 Suppl 1):S152-6.

19. Leist M, Ghezzi P, Grasso G, Bianchi R, Villa P, Fratelli M, et al. Derivatives of erythropoietin that are tissue protective but not erythropoietic. Science. 2004; 305:239-42.

20. Jubinsky PT, Krijanovski OI, Nathan DG, Tavernier J, Sieff CA. The beta chain of the interleukin-3 receptor functionally associates with the erythropoietin receptor. Blood. 1997;90:1867-73

21. Smith PD, Puskas F, Fullerton DA, Meng X, Cho D, Cleveland JC Jr, et al. Attenuation of spinal cord ischemia and reperfusion injury by erythropoietin. J Thorac Cardiovasc Surg. 2011;141:256-60.

22. Jung JE, Kim GS, Chen H, Maier CM, Narasimhan P, Song YS, et al. Reperfusion and neurovascular dysfunction in stroke: from basic mechanisms to potential strategies for neuroprotection. Mol Neurobiol. 2010;41:172-9.

23. Oshima Y, Fujio Y, Nakanishi T, Itoh N, Yamamoto Y, Negoro S, et al. STAT3 mediates cardioprotection against ischemia/reperfusion injury through metallothionein induction in the heart. Cardiovasc Res. 2005;65: 428-35.

24. Bolli R, Stein AB, Guo Y, Wang OL, Rokosh G, Dawn B, et al. A murine model of inducible, cardiac-specific deletion of STAT3: its use to determine the role of STAT3 in the up-regulation of cardioprotective proteins by ischemic preconditioning. J Mol Cell Cardiol. 2011;50:589-97.

25. Fu ZQ, Shao QL, Shen JL, Zhang YJ, Zhao XX, Yao L. Effect of carbamylated erythropoietin on major histocompatibility complex expression and neural differentiation of human neural stem cells. J Neuroimmunol. 2010;221:15-24.

26. Ehrenreich H, Degner D, Meller J, Brines M, Béhé M, Hasselblatt M, et al. Erythropoietin: a candidate compound for neuroprotection in schizophrenia. Mol Psychiatry. 2004;9:42-54.

27. Okita Y. Surgery for thoracic aortic disease in Japan: evolving strategies toward the growing enemies. Gen Thorac Cardiovasc Surg. 2015;63:185-96.

Key Words: spinal cord, ischemic reperfusion injury, thoracoabdominal aortic aneurysm

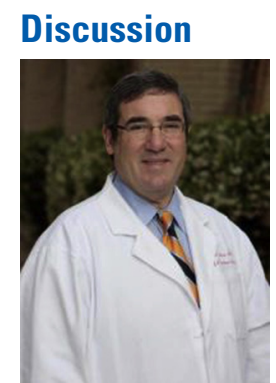

Dr R. Shemin. The next paper probably has the longest title: "Pretreatment with diazoxide enhances the neuroprotective function of erythropoietin against spinal cord ischemia and reperfusion injury through up-regulation of beta common receptor." The presenter is Dr Yamanaka, from the University of Colorado.

Dr Yamanaka (Denver, Colo). Hi, I really appreciate the WTSA and the moderator, guests, and members. I'm very happy to have this opportunity to present today. Thank you all for coming. Paraplegia remains a most dreadful complication of thoracoabdominal aortic intervention, and EPO attenuates this ischemic injury in various tissues. We previously reported a neuroprotective effect of EPO, and now we explore the different mechanism and the potential of EPO. Diazoxide has a functional preconditioning, so we believe that pretreatment with diazoxide will amplify the protective effect of EPO.

Regarding the EPO receptor, there are 2 types of receptor: hematopoietic and tissue protective receptors. This tissue protective receptor is called the beta common receptor. We have focused on this beta common receptor, but there is one problem. The protective effects of EPO are not seen until beta common receptor expression is induced by metabolic stress, so we hypothesize that pretreatment with diazoxide induces beta common receptor expression before ischemia. Diazoxide amplifies a neuroprotective effect of EPO in mouse with spinal cord ischemia and reperfusion injury. In terms of our mouse model of spinal cord ischemia, aortic arch, and left subclavian artery were clamped for 4 minutes, and during our aortic cross-cramping, we can see a more than $90 \%$ decrease in distal aortic flow. After surgery, mice showed an initial insult, recovery of motor function within a couple of hours, and paraplegia at around 36 hours after reperfusion.

We first performed a time trial test of diazoxide. The left bar graph shows beta common receptor, the expression of beta common receptor. The graph on the right one shows expression of the EPO receptor, so you can see that the expression of beta common receptor peaked at 36 hours after administration of diazoxide. On the other hand, the expression of EPO receptor remained unchanged. So we determined that diazoxide was given to the mice 36 hours before surgery, and the EPO was injected to the mice 4 hours before surgery. So, our experimental groups consisted of this ischemic control, just EPO group, just diazoxide group, diazoxide plus EPO combined treatment group, and sham. In these groups, we produced mice model of spinal cord ischemia. This line graph shows the postoperative motor function in each group, but 
vertical axis shows Basso Mouse Scale. Score 0 means no movement, and score 9 means normal motor function. Horizontal axis shows time after reperfusion. Sham mice had normal motor function, and all of the mice in this ischemic control group developed paraplegia at around 36 hours after reperfusion. And the motor function in the just diazoxide group worsened at around 24 hours after reperfusion. And in terms of 48 hours after reperfusion, diazoxide plus EPO combined treatment preserved the motor function significantly compared with other groups, and this is a histological analysis. This is a sham group. This purple one is a viable neuron, and this is an ischemic control, there were severe vascularizations and fewer viable neurons. Next, we compare the number of viable neurons in anterior horn. This bar graph shows a number of viable neurons. Mice treated with just the diazoxide or just EPO had more viable neurons than is ischemic control, and furthermore, mice treated with diazoxide plus EPO had most viable neurons significantly. And finally, this bar graph shows activation of AKT, STAT3, and CREB in diazoxide plus EPO group without surgery. To determine the mechanism neuroprotection we analyzed activation of AKT, STAT3, and CREB because AKT, STAT3, and CREB have important effect of their survival. We gave diazoxide here and we injected the EPO here, and we removed spinal cord at $0,1,2,4$, and 6 hours after injection of EPO, so you can see that the activation of AKT, STAT3, and CREB peaked at 4 hours after injection of EPO. So, we focused on this time point, and we compare the activation in each group. In terms of activation of AKT, diazoxide plus EPO increased significantly than other groups. Regarding about activation of STAT3, just EPO or just diazoxide increased activation of STAT3 significnatly than the ischemic control and furthermore, diazoxide plus EPO increased significantly comparing just EPO group or just diazoxide group. Regarding about activation of CREB, just EPO, just diazoxide, and combined treatment increased activation of CREB significantly than ischemic control but diazoxide plus EPO treatment group was highest.

In summary, pretreatment with diazoxide caused expression of beta common receptor without increasing the EPO receptor expression. Combined treatment preserves motor function dramatically. Combined treatment preserved both the functional injury and the cytoarchitectural change in the anterior horn. Activation of AKT and STAT3 were upregulated significantly in combined group. In conclusion, an expression of beta common receptor by diazoxide can increase efficacy of EPO in preventing the spinal cord ischemia on the reperfusion injury. Better understanding of this synergetic mechanism may allow for development of target specific therapy that can ameliorate ischemic complications during high-risk aortic interventions. Thank you for your attention.

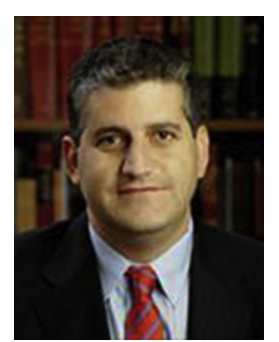

Dr F. Fleischman. Thank you and thank you for providing me with the presentation and the manuscript so I could review it. Thank you to the Western for having me discuss this important paper. As it pertains to... I also want to congratulate the Colorado group for their focus on this paraplegia risk in both the endovascular and open aortic group. So, I have two questions for you, the first being did you account for blood pressure and anesthesia effects after the pretreatment and after the cross-clamp group?

Dr Yamanaka. We previously reported the reproducible paraplegia model in mice. I consider blood pressure a limitation of this study, because intraoperative and postoperative close blood pressure control is not allowed. It is very difficult to check. However, instead of blood pressure we can check the distal aortic perfusion. Actually, we inserted the probe of laser the perfusion monitor over femoral artery and we can make sure more than $90 \%$ decrease in distal aortic flow. And there are no differences between groups, and the anesthesia we use is isoflurane and we use the same dosage of isofluane. There were no differences.

Dr Fleischman. Thank you. The second question is what do you see the clinical utility of a pretreatment that is required 36 hours before an aortic intervention, given that at least in our group, most aortic or a large portion of aortic interventions are in the acute setting?

Dr Yamanaka. Yeah, so in this project, we gave diazoxide 36 hours before surgery, so I think this method suits elective patients. Although this method doesn't suit emergent cases, but in order to extend the application we require further study.

Dr Fleischman. Thank you and congratulations.

Dr Yamanaka. Thank you.

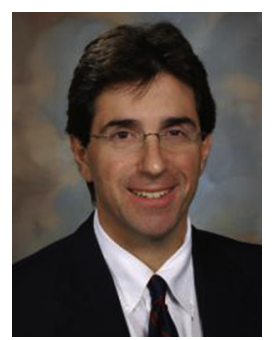

Dr C. Selzman (Salt Lake City, Utah). So, congratulations to you and to the whole group. I was just looking at one of your slides that I was just curious about. You followed these mice out for not very long, and I wonder if you have followed them out longer. In other words, is this treatment just delaying the inevitable, in that you're heading down this pathway and just because you stopped looking at these mice after 3 days, the paraplegia rates were different, because your curves... everything was like this, and then it went down. And so is this just delaying the inevitable or do you have some mice that you follow a little bit further?

Dr Yamanaka. Thank you for your question. This is an important point. Actually, we observed for 1 week, and 
today I showed 48-hour perfusion, but the motor function in diazoxide plus EPO combined treatment group didn't worsen, so I mean, the motor function was stable.

Dr Selzman. Did it make it back up to sham levels?

Dr Yamanaka. No. The 48 hours after the perfusion was stable, but the motor function on just diazoxide on the EPO group, some mice worsen, some mice were stable.

Dr Selzman. It sounds like you need to work on mouse rehab after this huh? No? Okay.

Dr Shemin. Thank you very much.

Dr Yamanaka. Thank you. 